\title{
Aristóteles e Bruce Wayne: uma aula sobre estética através do filme Batman (1989)
}

Aristotle and Bruce Wayne: a class on aesthetics through the film Batman (1989)

\author{
Bruno José Yashinishi \\ Professor no Colégio São Tomaz de Aquino, Wenceslau Braz, Paraná, Brasil. \\ yashinishibruno@outlook.com \\ ORCID: https://orcid.org/0000-0001-5243-7616
}

Recebido em 14 de julho de 2019

Aprovado em 07 de outubro de 2019

Publicado em 07 de janeiro de 2020

RESUMO: Aristóteles (384 a.C. - 322 a.C.), um dos principais filósofos da história, considerava a Arte como um instrumento pedagógico que possibilita repensar atitudes e tornar as pessoas melhores. Por meio da catarse, as obras trágicas são capazes de promover intensas reflexões sobre o caráter e o destino dos seres humanos. Nesse sentido, o presente artigo objetiva elucidar as concepções aristotélicas sobre a Estética através do filme Batman (1989), de Tim Burton. A proposta é relacionar a história do personagem Bruce Wayne com o conceito aristotélico de catarse, utilizando o filme como recurso didático nas aulas de Filosofia para séries do Ensino Médio.

Palavras-chave: Ensino de Filosofia; Filosofia e cinema; Estética; Aristóteles.

ABSTRACT: Aristotle (384 BC - $322 \mathrm{BC}$ ), one of the leading philosophers of history, considered Art as a pedagogical instrument that makes it possible to rethink attitudes and make people better. Through catharsis, tragic works are capable of promoting intense reflections on the character and destiny of human beings. In this sense, the present article aims to elucidate the Aristotelian conceptions of Aesthetics through the film Batman (1989), by Tim Burton. The proposal is to relate the story of the character Bruce Wayne with the Aristotelian concept of catharsis, using the film as didactic resource in Philosophy classes for high school series. Keywords: Philosophy Teaching; Philosophy and cinema; Aesthetics; Aristotle.

\section{Introdução}

O presente artigo pretende suscitar reflexões teóricas e possibilidades metodológicas de promover o ensino de Filosofia no Ensino Médio através do cinema. Neste caso, o filme Batman (1989) será utilizado como aporte didático para a compreensão de conceitos relacionados à Estética no pensamento de Aristóteles (384 a.C. - 322 a.C.). 
Estética é um termo derivado do grego que significa sensação, sentimento ${ }^{1}$. Na Filosofia, corresponde ao estudo da arte e do belo e atribui-se sua adoção como "doutrina do conhecimento sensível" a Alexander Baugarten (1714-1762) no século XVIII (SCHÖPKE, 2010).

O filme Batman, de Tim Burton, apresenta o drama sofrido pelo personagem Bruce Wayne ainda na infância, que o levou a se engajar no combate ao crime valendose de uma fantasia que representa um de seus maiores medos na figura do morcego. A cena em que os pais de Bruce são assassinados por criminosos pode levar os espectadores do filme a uma catarse, do grego kathársis, que tem o sentido de purificação ou purgação e, para Aristóteles, designa o efeito da mimese nas representações trágicas.

Nesse sentido, em sala de aula, torna-se possível associar o filme selecionado com a Estética aristotélica, já que Batman pode promover nos alunos a catarse ao acompanharem e se identificarem com os dramas vividos pelo personagem principal do filme, Bruce Wayne, próprios de um herói trágico.

Rogério de Almeida (2017), elucidando os fundamentos educativos do cinema em uma abordagem hermenêutica apresenta algumas importantes concepções sobre o uso do filme em sala de aula, como por exemplo, adotar a produção cinematográfica como forma de conhecimento e como ferramenta didática para o ensino. $O$ autor também aponta que a relação entre cinema e educação deve estar fundamentada em sete aspectos primordiais: cognitivo, filosófico, estético, mítico, existencial, antropológico e poético. Entretanto, Almeida não oferece alternativas metodológicas mais práticas para o trabalho com filmes no ambiente escolar.

O historiador Marcos Napolitano (2009) sugere que o professor prepare antecipadamente seu planejamento de atividades e indica alguns procedimentos importantes na formulação de um roteiro de aula que utilize um filme como recurso didático através de duas fases: o plano de atividades e a análise do filme.

Na primeira fase, o professor deve pensar no emprego do filme dentro de um planejamento geral, em seguida deve selecionar o filme a se trabalhado, procurar informações básicas sobre o filme e conhecer a cultura cinematográfica da classe. Na segunda fase, o filme não deve ser exibido imediatamente em sala de aula, mas antes, deve-se fornecer um roteiro de análise para os estudantes, valendo-se de textos de apoio. Em seguida, deverão ser formados grupos de discussão sobre a proposta do filme que elaborem uma síntese relacionando a obra cinematográfica com o conteúdo estudado (NAPOLITANO, 2009).

Pensando nessas orientações referentes às possibilidades teóricas e metodológicas do uso do cinema em sala de aula, o objetivo geral deste artigo, é apresentar aos professores de Filosofia, bem como aos demais leitores interessados na relação entre Cinema, Filosofia e Educação, um roteiro específico para uma aula temática sobre a Estética aristotélica utilizando o filme Batman.

Para tanto, o artigo tem três objetivos específicos que perfazem a elaboração do roteiro de aula, já que este será estruturado basicamente em três partes: Parte Informativa, Parte Interpretativa e Parte Formativa, conforme modelos propostos pelos autores Diego Augusto Doimo e Raimunda Abou Gebran no artigo A Filosofia no Ensino Médio: o Cinema como recurso didático (2018). 


\section{Cinema e Filosofia em sala de aula}

A relação entre Cinema e Filosofia pode ser analisada em dois sentidos: aquilo que, na Filosofia, interessa ao Cinema e aquilo que, no Cinema, interessa à Filosofia (RIBAS; CENCI, 2007). As autoras Maria Lúcia de Arruda Aranha e Maria Helena Pires Martins (2003) afirmam que a Filosofia é um modo de pensar que acompanha o ser humano na empreitada de compreender e agir sobre o mundo.

Entendendo a Filosofia como processo, como uma reflexão crítica e autônoma sobre a própria vida, pode-se afirmar que, para além de um campo disciplinar do saber, ela se configura enquanto uma atividade do homem na elaboração de ideias gerais sobre a realidade e os seres humanos e caracteriza-se com aspectos analíticos, reflexivos e críticos na busca do fundamento e do sentido da realidade em suas múltiplas formas (CHAUÍ, 2010).

No entanto, a Filosofia não se restringe à mera abstração, mas ancora-se e busca na realidade os objetos de sua investigação, mantendo uma íntima relação com a realidade vivida. A realidade, porém, possui uma multiplicidade de perspectivas, representada pelas diversas correntes do pensamento filosófico. Nesse aspecto, a particularidade da Filosofia frente a outros campos do saber é que ela não possui um objeto específico de investigação, muito menos respostas definitivas para as questões da realidade. Karl Jaspers (1883-1969) dizia que "as perguntas em filosofia são mais essenciais que as respostas e cada resposta transforma-se numa nova pergunta" (1971, p.140).

Pode-se observar que não há uma finalidade de ordem pragmática na reflexão filosófica, todavia essa particularidade não a torna desnecessária, mas pode assemelhá-la com a arte, que possui um fim em si mesma (ARANHA; MARTINS, 2003). Stephenson e Debrix (1969) elucidam a relação entre arte e realidade sob três pontos: o primeiro é que o artista tira inspiração ou intuição artística de sua própria vida, configurada enquanto realidade no conjunto de experiências do cotidiano; o segundo é que a arte se expressa por um determinado veículo físico, que se combina com a experiência do artista; o terceiro ponto é que a arte deve ser apresentada ao público "real", ou seja, atingir o mundo real de onde emergiu.

Diante destas colocações, os autores afirmam que o cinema pode ser considerado como uma expressão artística legítima e que também possui relação com a realidade, ao passo que acarreta em si os três aspectos mencionados anteriormente: "Como qualquer outra arte, a realização de um filme pode ser analisada à base da intuição, execução e exibição" (STEPHENSON; DEBRIX, 1969, p.24).

Entretanto, são pertinentes as indagações se o cinema é uma arte do real ou se é capaz de reproduzir o movimento da vida. Para Jean-Claude Bernadet (2006), o campo de visão humana é maior do que o espaço da tela, a imagem cinematográfica não a reproduz realmente. Além disso, o movimento do cinema é ilusório, sendo que o que se vê na tela na verdade são fotografias projetadas num ritmo de 24 fotogramas por segundo. Nesse sentido, não se deve esquecer que o filme é um artefato da reprodutibilidade técnica como ressalta Walter Benjamin: 
Fotografar um quadro é um modo de reprodução; fotografar num estúdio um acontecimento fictício é outro. No primeiro caso, o objeto reproduzido é uma obra de arte, e a reprodução não o é. (...) Na melhor das hipóteses, a obra de arte surge através da montagem, na qual cada fragmento é a reprodução de uma acontecimento que nem constitui em si uma obra de arte, nem engendra uma obra de arte, ao ser filmado (BENJAMIN, 1994, p.177-178).

Todavia, para além do debate sobre considerar o cinema como arte ou não, o mais importante aqui é compreender quais as possibilidades de relação entre o filme e a reflexão filosófica. Ao contrário do que defendem alguns teóricos, como Marshall Mcluhan (1969), por exemplo, o espectador do cinema não aceita tudo que a câmera mostra subliminarmente e desprovido de consciência crítica. Um filme não oferece apenas entretenimento, mas, assim como a literatura, é capaz de "tornar presente o ausente, próximo o distante, entrecruzando realidade e sonho, verdade e fantasia, reflexão e devaneio, alterando de maneira lúdica o tempo e o espaço" (SOBRAL, 2011, p. 165).

Sob esse prisma, ainda que seja composto por manipulação, aspectos industriais e mercadológicos, um filme pode estimular no espectador uma reação que vá além da passividade e que propicie reflexões sobre as mais diversas questões da vida humana, bem como de experiências pessoais do cotidiano:

O cinema pode servir como mola propulsora, como o aguilhão da atividade filosófica, na medida em que possibilita mediante a realidade ficcional posta, causar a afetação necessária que põe em marcha um processo de intelecção da problemática experiência da na trama. Essa dimensão cognitiva do cinema, que vai além do lazer, possibilita uma compreensão do mundo (RIBAS; CENCI, 2007, p. 4).

O cinema é capaz de provocar no espectador o espanto e a admiração, ambas condições fundamentais para a reflexão filosófica como afirmavam Platão e Aristóteles. Mais do que a busca pela reprodução do real em suas imagens, o cinema proporciona a produção de saber e de sentidos e sua linguagem particular potencializa a capacidade de reflexão, de compreensão e de sintetizar a emoção e a razão, a realidade e o imaginário. Dessa forma, o cinema pode ultrapassar a convencional função de entretenimento ou indústria e se configurar como um lugar privilegiado do pensamento, capaz de proporcionar reflexões filosóficas (ALMEIDA, 2015).

São essas reflexões filosóficas que o uso do filme Batman (1989) como recurso didático em aulas de Filosofia no Ensino Médio pode promover a respeito das concepções sobre Estética oriundas do pensamento de Aristóteles. Entretanto, essa capacidade depende de como o professor direciona as atividades de análise presentes na película. Sendo assim, o roteiro de aula e seu processo de elaboração que serão apresentados a seguir pretendem valer como uma sugestão didática aos docentes. 


\section{Uma sugestão didática: a construção do Roteiro de Aula}

Doimo e Gebran (2018) afirmam o Cinema é capaz de construir uma visão crítica e reflexiva quando a utilização de filmes que se apropriam de uma linguagem metafórica associa-se a temas filosóficos. Dessa maneira, os autores elaboraram uma estrutura para roteiro de aula (Quadro I):

Quadro I: Roteiro de aula

\begin{tabular}{|l|l|}
\hline \multicolumn{1}{|c|}{ Momentos e elementos } & \multicolumn{1}{c|}{ Objetivos } \\
\hline 1 - ANTES & Fornecer informações básicas do filme: \\
& $\begin{array}{l}\text { - Ficha técnica } \\
\text { - Sinopse } \\
\text { - Personagens principais (elenco) }\end{array}$ \\
\hline $\begin{array}{l}2 \text { - DURANTE } \\
\text { Parte Interpretativa }\end{array}$ & $\begin{array}{l}\text { Direcionar o olhar do aluno para aspectos importantes do filme por } \\
\text { meio de questões que o levem a refletir filosoficamente através dos } \\
\text { quatro passos didáticos: } \\
\text { - Sensibilização } \\
\text { - Problematização } \\
\text { - Investigação } \\
\text { - Conceituação }\end{array}$ \\
\hline $\begin{array}{l}3 \text { - DEPOIS } \\
\text { Parte Formativa }\end{array}$ & $\begin{array}{l}\text { Referenciar o conteúdo ou tema trabalhado no Currículo de Filosofia } \\
\text { a ser desenvolvido a partir do filme exibido, podendo utilizar-se: } \\
\text { - Material de Apoio ao Currículo } \\
\text { - Livro Didático } \\
\text { - Atividade Complementar ao Filme }\end{array}$ \\
\hline
\end{tabular}

Fonte: DOIMO; GEBRAN, 2018, p. 64.

Tomando como base o modelo proposto acima segue a construção do roteiro de uma aula que contemple o uso do filme Batman como recurso didático para se entender a concepção de Estética em Aristóteles.

\section{Parte Informativa}

O primeiro momento do roteiro de aula é sua Parte Informativa, onde o professor (a) deve analisar e fornecer informações básicas sobre o filme selecionado para sua aula (DOIMO; GEBRAN, 2018).

Batman é um filme estadunidense de 1989, dirigido por Tim Burton e baseado no personagem homônimo da DC Comics, sendo o primeiro longa metragem da Warner Bros sobre o herói criado pelo escritor Bill Finger e pelo artista Bob Kane (BERRY, 2008).

O filme começa com as aventuras noturnas de Batman (Michael Keaton) combatendo criminosos e fazendo justiça com as próprias mãos na sombria cidade fictícia de 
Gotham City. Nem mesmo as autoridades conhecem a verdadeira identidade do homem disfarçado de morcego, que até então se apresenta como uma figura ambígua, pois espalha o medo pela cidade ao mesmo tempo em que ajuda no combate ao crime. $O$ espectador, no entanto, já sabe que Batman é o bilionário Bruce Wayne, um dos homens mais influentes de Gotham, dono da Wayne Enterprises e um socialite nada modesto.

Gotham City está tomada pela criminalidade, chefiada por Carl Grissom (Jack Palance) que controla gangues de extermínio e corrompe policiais. Os esforços do promotor Harvey Dent (Billy Dee Williams) e do comissário Gordon (Pat Hingle) em combater o crime parecem inúteis sem a ajuda não solicitada do herói mascarado. Batman suscita apreensão dos bandidos e o interesse de jornalistas como Alexander (Robert Wuhl) e a jovem Vicki Vale (Kim Basinger).

O braço direito de Grissom é o criminoso Jack Napier (Jack Nicholson), um homem extremamente perigoso, mas que seria dotado de lealdade se não fosse pelo fato de ter relações com a mulher do chefe. Quando Grissom descobre a traição, arma uma emboscada para Jack em uma fábrica de produtos químicos por meio de um cerco policial já premeditado. Napier consegue fugir dos policiais, mas é surpreendido por Batman e, em meio a uma perseguição, é ferido no rosto e acaba caindo acidentalmente em um tanque com substâncias químicas. A reação da queda no meio dessas substâncias causam alterações no rosto e na pele de Jack, transformando-o no que virá a ser o principal inimigo de Batman: o Coringa.

$\mathrm{Na}$ noite seguinte, Jack (agora Coringa) aparece de surpresa no escritório de Carl Grissom e o mata, tornando-se assim o chefe do crime. Coringa enlouquece e pretende se vingar de Batman, bem como de toda Gotham City, espalhando a substância química que o deformou através de cosméticos de beleza para toda a população.

Enquanto isso, Bruce Wayne conhece a jornalista Vicki e se apaixona por ela. A jovem continua obstinada a encontrar a verdadeira identidade de Batman e só descobre que é Bruce através de Alfred (Michael Gough), o fiel mordomo e tutor da família Wayne. A relação entre Bruce e Vicki fica conturbada devido à dupla personalidade do senhor Wayne. No entanto, Coringa também se apaixona por Vicki e a sequestra invadindo a casa de Bruce, que agora tem uma dupla missão: salvar a mulher amada como Bruce Wayne e salvar Gotham City dos crimes do Coringa como Batman.

Nesse meio tempo, Bruce tem uma revelação recordando o acontecimento trágico envolvendo a morte de seus pais. Quando era criança, voltava de um espetáculo com sua família durante a noite e foi surpreendido por dois ladrões, sendo que um deles disparou tiros contra seu pai e sua mãe levando-os a óbito. $O$ pequeno Bruce presenciou tudo e identificou o assassino como sendo Jack Napier, o Coringa.

No fim do filme, Batman impede que seu inimigo espalhe um gás letal sobre a população da cidade, consegue resgatar sua amada e vê Coringa despencar para a morte da torre da catedral de Gotham. Por se apresentar como herói, Batman alcança a redenção do povo e das autoridades, que de agora em diante irão chamá-lo por meio de um sinal de luz no céu com o símbolo do morcego. 


\section{Parte Interpretativa}

Na segunda parte do roteiro de aula, Doimo e Gebran (2018) propõem que os alunos sejam orientados a refletir filosoficamente sobre aspectos importantes do filme. Evidentemente, como se trata de uma aula da disciplina de Filosofia é inviável a exibição do filme completo em sala de aula, portanto serão exibidas algumas cenas previamente selecionadas atendendo aos quatro passos didáticos mencionados pelos autores (Sensibilização, Problematização, Investigação e Conceituação) e norteadas por questões específicas:

\section{- Cena 03:50 minutos (Sensibilização)}

Por que Batman combate os criminosos de Gotham durante a noite?

- Cena 06:40 minutos (Problematização)

Batman tem uma identidade secreta. Por que, no entanto, obstina-se a ser conhecido pelos criminosos?

- Cena 29:50 minutos (Investigação)

Que influência teve a morte de Bruce para que ele se tornasse o Batman?

- Cena 54:55 minutos (Conceituação)

Por que Batman diz ao Coringa que foi ele quem o criou e não o contrário?

\section{Parte Formativa}

Nesta última parte do roteiro, deve-se referenciar o tema trabalhado no currículo de Filosofia e sua relação com as cenas do filme exibidas aos alunos. Neste caso, foram adotadas algumas sugestões bibliográficas que, de forma bastante didática, abordem três pontos fundamentais: 1 - As concepções de Estética provindas do pensamento aristotélico; 2 - O conceito de catarse para Aristóteles; 3 - A relação entre o conteúdo estudado e o personagem Batman. Essa bibliografia não necessariamente será apresentada de forma direta ao aluno, mas antes serve como referencial teórico que o (a) professor (a) deve ter conhecimento para alcançar os objetivos propostos para a aula.

A Poética, de Aristóteles, tem sido uma das principais referências nos estudos sobre a filosofia da Arte. A obra teve grande influência nos estudos literários e na oratória até o século $\mathrm{XV}$. Após o Renascimento italiano, a escultura e a pintura adquiriram um status de belas artes, semelhante ao das artes poéticas, o que aumentou o alcance da contribuição aristotélica para reflexões sobre demais expressões artísticas (SANTORO, 2007). No primeiro livro, o filósofo analisa o modo de ser e proceder da epopeia e da tragédia, no segundo, provavelmente tratou da comédia e da sátira, já que essa parte do texto acabou se perdendo com o tempo.

Vale lembrar que a Estética, enquanto teoria do belo artístico é uma concepção filosófica moderna, que se preocupa com os juízos de valor sobre o belo sensível provindo das obras de arte. A Poética de Aristóteles, no entanto, se preocupa mais com os saberes empregados na produção do belo sensível e a finalidade dessa produção: 
De fato, a Poética de Aristóteles, menos do que um tratado de arte, de saber fazer e produzir o belo, é já uma investigação filosófica que implica, além de considerações sobre o fazer poético, a avaliação da inserção prática das artes na formação e elevação espiritual dos homens; e neste sentido, importaIhe muito o efeito produzido, i.e., como o manifestar-se da obra afeta o homem, o espectador da obra (SANTORO, 2007, p. 5).

Segundo Aristóteles, a criação artística nasce do impulso formativo e da expressão emocional. O objetivo da arte seria "representar não a aparência externa das coisas, mas seu significado interno" (DURANT, 2000, p. 89). Nesse sentido, diferentemente do que pensava seu mestre Platão, Aristóteles afirmava que o ser humano imitava a realidade porque gostava de aprender.

A mímesis aristotélica é um contraponto à mímesis de Platão, não define o valor artístico (baixo) mas vem resgatar o valor de verdade: se, para Platão, a imitação era o distanciamento da verdade e o lugar da falsidade e da ilusão, para Aristóteles, a imitação é o lugar da semelhança e da verossimilhança, o lugar do reconhecimento e da representação (SANTORO, 2007, p. 6).

A mímesis não seria apenas a produção de cópias, mas sim de obras criativas que melhoram ou pioram os modelos reais, ou, ainda, de acordo com as intenções do artista, representam aspectos universais da vida humana através de histórias sem compromisso direto com a realidade.

Dentre tantas contribuições do pensamento aristotélico presentes em Poética ressaltam-se as análises que o filósofo faz sobre a Comédia e a Tragédia. "A comédia é, como já dissemos, imitação de maus costumes, mas não de todos os vícios; ela só imita aquela parte do ignominioso que é o ridículo" (ARISTÓTELES, 2013 , p. 28). Para Aristóteles, ao ridicularizar as pessoas, o poeta cômico podia criticar os defeitos de caráter e erros de conduta que prejudicariam a vida nas cidades. Quanto à Tragédia: "Suscitando a compaixão e o terror, a tragédia tem como efeito obter a purgação dessas emoções" (ARISTÓTELES, 2013, p.29). As obras trágicas, além de suscitarem reflexões sobre o caráter e destino humano também seriam capazes de promover a purificação das paixões, estimulando a catarse.

O termo grego kathársis, traduzido como catarse significa purificação ou purgação. Advindo dos contextos médico e religioso, foi adotado por Aristóteles para designar um possível efeito da mimese nas representações trágicas:

Em geral, o teatro, a música e a poesia têm a capacidade de produzir tal purificação, embora a tragédia (talvez por reunir esses três elementos) seja a que melhor promova essa "limpeza interior". Afinal, como nos mostra Aristóteles, uma verdadeira simpatia liga o espectador ao herói, cuja dor e sofrimento 
Para Aristóteles: "A tragédia consiste, pois, na imitação de uma ação e é, sobretudo, por meio da ação que ela imita as personagens em movimento" (2013, p.32). A arte consiste na imitação da natureza no ato de criar, já que Aristóteles a considerava como poiesis ${ }^{2}$ (ARANHA; MARTINS, 2003).

O efeito da Tragédia consiste em amenizar emoções extremas, como o temor ou a compaixão, pelo equilíbrio entre a identificação do espectador com a condição da personagem representada ou ainda pelo distanciamento em relação ao drama enfrentado por ela na representação trágica. Nesse sentido, o espectador não seria vítima da tragédia, mas sim contemplaria a imagem de uma, o que possibilitaria o aprendizado sobre a condição e destino dos seres humanos.

Em Batman (1989), a origem do super-herói ocorre por meio de um acontecimento trágico. À noite, o casal Wayne é assaltado por dois bandidos que surgem da escuridão das ruas de Gotham. Bruce, um menino indefeso, assiste sem reação a morte dos pais com tiros disparados por um dos criminosos. Tim Burton, diretor do filme, optou por caracterizar o assassino como Jack Napier, que posteriormente se tornaria o Coringa, mas esse dado não consta nos quadrinhos e na história original de Batman. No entanto, a partir daquela noite, Bruce irá carregar pelo resto de sua vida o trauma da violência urbana e o medo da escuridão.

A história de Batman é uma espécie de Tragédia. De acordo com Ariano Suassuna (2013), a Tragédia comporta seis pontos essenciais: a ação trágica, a linguagem trágica, o personagem trágico, a decisão e o conflito, o infortúnio e o terror e a piedade. Evidentemente, o autor refere-se às peças trágicas do teatro, mas a história de Batman também apresenta essas características.

Para Aristóteles: "A tragédia é a imitação de uma ação importante e completa, de certa extensão" (2013, p.29). Suassuna argumenta que essa ação é de caráter elevado, ou seja, uma ação não comum em que esteja implicado um princípio de ordem superior. A importância da ação para a Tragédia é evidenciada na obra de Aristóteles:

A imitação de uma ação é o mito (fábula); chamo fábula a combinação dos atos; chamo caráter (ou costume) o que nos permite qualificar as personagens que agem; enfim, o pensamento é tudo o que nas palavras pronunciadas expõe o que quer que seja ou exprime uma sentença (2013, p. 30).

A ação trágica no filme Batman, sobretudo na cena em que os pais de Bruce são assassinados, corresponde ao fundamento do destino reservado à personagem. Aristóteles sentencia que "Sem ação não há tragédia" (2013, p. 31).

O aspecto sombrio e dramático da cena do assassinato do casal Wayne evidencia a linguagem trágica, utilizando recursos particulares da linguagem cinematográfica, tais 
como trilha sonora e efeitos visuais. O escuro, o silêncio, o som dos passos, dos gritos da mãe de Bruce, dos tiros e, por fim, o rosto do bandido saindo da escuridão. Ariano Suassuna afirma que, para Aristóteles, a linguagem trágica deve ser poética, onde a imagem e a metáfora predominam sobre a precisão e a clareza. Nesse aspecto, a ambientação criada nesta cena do filme denota a metáfora da impotência do bem (Bruce) diante do mal (Napier), mas sugere que o senso de justiça vai florescer apesar da situação.

Bruce vai viver dali em diante com o propósito de combater o mal. Quando se torna adulto, vive uma vida dupla que oscila entre manter sua personalidade extravagante de um dos maiores magnatas de Gotham e manter em segredo a personalidade de combatente do crime fantasiado de morcego. Batman não é um herói comum. Veste-se como um animal noturno porque sua verdadeira identidade foi marcada por um medo traumático da noite. Aqui, Bruce Wayne figura-se como um personagem trágico.

"O personagem trágico tem caráter que é uma mistura de boas e más qualidades" (SUASSUNA, 2013, p. 52). Esse personagem trágico carrega em si a decisão e o conflito. Como possuidor de um caráter excepcional, Bruce não se acomodou com a fortuna e os prazeres de uma vida cheia de privilégios, mas optou por arriscar-se no combate ao crime: "As pessoas comuns escolhem sempre o caminho mais tranquilo e seguro; as personalidades trágicas escolhem os de maior perigo, os mais arriscados e cheios de grandeza" (SUASSUNA, 2013, p. 53).

Bruce Wayne e Batman são interligados constantemente pela decisão e pelo conflito. Graças ao infortúnio do personagem ainda na infância, sua vida destina-se a enfrentar seu maior medo, a morte. O infortúnio do personagem é essencial ao trágico. Suassuna argumenta que:

Todo esse encadeamento - ação elevada, caráter trágico, decisão e conflito - termina, na tragédia, conduzindo o personagem ao esmagamento, ao infortúnio, ao aniquilamento. Essa má fortuna do personagem não se identifica necessariamente com a morte, se bem que a morte seja o remate mais normal dos fatos, escolhas e ações em que se envolve o personagem (SUASSUNA, 2013, p. 53).

De maneira objetiva, o Trágico decorre de uma ação humana elevada, onde o personagem excepcional deve fazer escolhas entremeio a conflitos e infortúnios. De maneira subjetiva, o Trágico desencadeia no espírito humano o terror e a piedade, determinando a purificação das paixões (SUASSUNA, 2013). Na Poética, Aristóteles afirma que a Tragédia deve produzir o terror e a piedade por meio do próprio encadeamento das ações.

No final desta etapa, os alunos realizarão uma atividade que os levem a compreender o conceito de catarse e a função da arte trágica para o filósofo Aristóteles relacionando com o filme assistido. 


\section{O Roteiro de Aula construído: modelo}

Após seguir passo a passo a construção do roteiro de aula, o modelo a seguir (Quadro II) oferece um panorama geral da aula sugerida neste artigo:

Quadro II: Roteiro de Aula

\section{Parte Informativa}

Ficha técnica

- Título: Batman

- Gênero: Ação/Fantasia

- Direção: Tim Burton

- Ano: 1989

- Duração: 126 minutos

- País: Estados Unidos

- Distribuidora: Warner Bros

- Classificação Indicativa: 12 anos

\section{Sinopse}

Após testemunhar a morte brutal de seus pais quando criança, o milionário filantropo Bruce Wayne luta contra o crime na cidade de Gotham disfarçado do herói Batman, que coloca medo nos corações dos vilões. Mas quando um louco e deformado que se auto intitula Coringa começa a controlar o submundo do crime em Gotham, Batman precisa encarar seu mais perverso inimigo para proteger sua identidade e a mulher que ama, a repórter Vicki Vale.

Personagens principais (elenco)

- Batman/Bruce Wayne (Michael Keaton)

- Jack Napier/Coringa (Jack Nicholson)

- Vicki Vale (Kim Basinger)

- Alexander Knox (Robert Wuhl)

- Comissário Gordon (Pat Hingle)

- Harvey Dent (Billy Dee Williams)

- Alfred (Michael Gough)

\section{Parte Interpretativa}

- Cena 03:50 minutos (Sensibilização)

Por que Batman combate os criminosos de Gotham durante a noite?

- Cena 06:40 minutos (Problematização)

Batman tem uma identidade secreta. Por que, no entanto, obstina-se a ser conhecido pelos criminosos?

- Cena 29:50 minutos (Investigação)

Que influência teve a morte de Bruce para que ele se tornasse o Batman?

- Cena 54:55 minutos (Conceituação)

Por que Batman diz ao Coringa que foi ele quem o criou e não o contrário?

\section{Parte Formativa}

\section{Série: $2^{\mathrm{a}}$ Série do Ensino Médio}

Habilidade: Relacionar as cenas analisadas com o conteúdo referente à concepção estética de Aristóteles.

Atividade: $O$ objetivo dessa atividade é compreender o conceito de catarse e a função da arte trágica para o filósofo Aristóteles. Haverá uma discussão em grupos relacionando Batman, como herói trágico, e o drama vivido pelo personagem com o efeito da mimese na produção de identificação dos alunos com a história e os sentimentos de piedade e temor proporcionados pelo efeito catártico das cenas.

Fonte: DOIMO; GEBRAN, 2018. p.66-67. 


\section{Considerações finais}

Diante do exposto neste artigo, conclui-se que para Aristóteles, as artes trágicas estimulam a catarse, ou seja, a purificação das paixões despertadas pelo enredo, sobretudo a piedade e o temor. Além disso, a concepção aristotélica de Estética aponta para a função pedagógica da Arte de direcionar as pessoas à reflexão.

Sendo a Estética, um dos conteúdos da disciplina de Filosofia no Ensino Médio, buscouse propor reflexões teóricas e procedimentos metodológicos de se adotar o Cinema em sala de aula como possível recurso didático que auxilie no aprendizado sobre o conteúdo em questão.

Por meio do roteiro de aula proposto e pela adoção do filme Batman, de Tim Burton, se pretende oferecer aos alunos a catarse ao acompanharem e se identificarem com os dramas vividos pelo personagem principal do filme, Bruce Wayne, em suas escolhas, conflitos e infortúnios, próprios herói trágico, como demonstrou Ariano Suassuna (2013).

\section{Referências}

ALMEIDA, Jorge Miranda de. Diálogo entre a Filosofia e o Cinema. ALCEU . v. 15, n.30, p. 168 a 181, jan./jun. 2015.

ALMEIDA, Rogério de. Cinema e Educação: fundamentos e perspectivas. Educação em Revista (UFMG), v. 33, p. 1-27, 2017.

ARANHA, Maria Lúcia de Arruda; MARTINS, Maria Helena Pires. Filosofando: Introdução à Filosofia. São Paulo: Moderna, 2003.

ARISTÓTELES. Poética e Tópicos I, II, III e IV. São Paulo: Hunter Books, 2013.

BATMAN. Direção: Tim Burton. Produção: Jon Peters e Peter Guber. Intérpretes: Michael Keaton; Jack Nicholson; Kim Basinger e outros. Roteiro: Sam Hamm

e Warren Skaaren. Música: Danny Elfman. Estados Unidos: Warner Brothers, 1989. 1 DVD (126 min).

BENJAMIN, Walter. A Obra de Arte na Era de Sua Reprodutibilidade Técnica. In.

BENJAMIN, Walter. Magia e Técnica, Arte e política. Obras escolhidas I. Trad. Rouanet S. P. São Paulo: Brasiliense, 1994. p. 165-196.

BERNADET, Jean-Claude. O que é Cinema. São Paulo: Brasiliense, 2006.

BERRY, Joanna. Batman (1989). In: SCHNEIDER, Steven Jay (Ed.). 1001 filmes para ver antes de morrer. Rio de Janeiro: Sextante, 2008. p. 770.

CHAUÍ, Marilena. Iniciação à Filosofia. São Paulo: Ática, 2010.

COTRIM, Gilberto; FERNANDES, Mirna. Fundamentos de Filosofia. São Paulo: Saraiva, 2013. 
DOIMO, Diego Augusto; GEBRAN, Raimunda Abou. A Filosofia no Ensino Médio: o Cinema como recurso didático. In: Educação em Revista, Marília, v.19, n.1, p. 53-70, Jan.-Jun., 2018.

DURANT, Will. A História da Filosofia. São Paulo: Nova Cultural, 2000.

JASPERS, Karl. Introdução ao pensamento filosófico. São Paulo: Cultrix, 1971.

MCLUHAN, Marshall. Os meios de comunicação como extensões do homem. São Paulo: Cultrix, 1969.

NAPOLITANO, Marcos. Como usar o cinema na sala de aula. São Paulo: Contexto, 2009.

RIBAS, Maria Alice Coelho; CENCI, Márcio Paulo. Filosofia e cinema: possíveis entrecruzamentos. Thaumazein, v.1, n.1, 2007, p.1-9. Disponível em: http://www.periodicos.unifra.br/ index.php/thaumazein/article/view/193/pdf. Acesso em: 30 de janeiro de 2019.

SCHÖPKE, Regina. Dicionário filosófico: conceitos fundamentais. São Paulo: Martins Fontes, 2010.

SANTORO, F. Sobre a estética de Aristóteles. In: Viso: Cadernos de estética aplicada, v. I, n. 2, mai. ago. 2007, p. 1-13.

SOBRAL, Osvaldo José. Ensaio Sobre Cinema: Uma Perspectiva Psicossocial da Sétima Arte. Revelli: Revista de Educação, Linguagem e Literatura da UEG-Inhumas, v. 3, p. 164/11-169, 2011.

STHEPENSON, Ralph; DEBRIX, Jean R. O cinema como arte. Rio de Janeiro: Zahar, 1969.

SUASSUNA, Ariano. Iniciação à Estética. Rio de Janeiro: José Olympio, 2013.

\section{Notas}

1 O termo grego aisthesis significa percepção pelos sentidos, sensação. Dele se formou a palavra aisthetikos: "que se percebe pelos sentidos" (COTRIM; FERNANDES, 2013).

${ }^{2}$ A poiesis significa "fazer", ou seja, o ato de criar algo que não existia antes. Para Aristóteles, a Arte é poiesis por ser uma criação de algo, já que todas as práticas humanas, desde a agricultura até as "belas artes" são consideradas por ele como Arte.

\section{Correspondência}

Bruno José Yashinishi - Rua Coronel Francisco Lopes, 874, Centro, CEP: 84980-000, São José da Boa Vista, Paraná, Brasil.

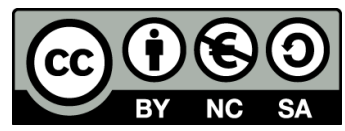

This work is licensed under a Creative Commons Attribution-NonCommercial 4.0 International (CC BY-NC 4.0) 